\title{
Weed Identification using Ultrasonic Sensor in Labview
}

\author{
K. C. Swain ${ }^{* 1}$, R. Moitra ${ }^{1}$ and Q. U. Zaman ${ }^{2}$
}

${ }^{1}$ Dept. of ASEPAN, Palli Siksha Bhavana, Visva-Bharati, Sriniketan, West Bengal (731 236), India

${ }^{2}$ Dept. of Engineering, Nova Scotia Agriculture College, Truro, Nova Scotia (B2N 5E3), Canada

\section{Article History}

Manuscript No. AR853

Received in $21^{\text {st }}$ July, 2014

Received in revised form $15^{\text {th }}$ December, 2014

Accepted in final form $25^{\text {th }}$ January, 2015

\section{Correspondence to}

*E-mail: swainkc@yahoo.com

\section{Keywords}

Ultrasonic sensor, wild blueberry, weeds, precision farming

\begin{abstract}
The presence of weeds and pests in the crop field is a common phenomenon. The success of site-specific pest management depends on accurate identification of the pest and weeds in crop field. An innovative low-cost ultrasonic sensor system was developed to detect weeds and bare spots in wild blueberry cropping system. Ultrasonic sensors were mounted besides the rear wheels of the specially designed Farm Motorized Vehicle. Trimble Ag GPS 332 was mounted above the sensors to locate the exact locations of sensor data points for mapping. Custom software interface was developed in Lab View 8.5 to collect and store the sensor data along with DGPS co-ordinates in a laptop computer. The ultrasonic system calibrated using the fixed height objects in the laboratory and vegetation in the wild blueberry fields. Linear regression analysis showed significant relationship between actual heights and sensor heights $\left(\mathrm{R}^{2}=0.98\right)$. The survey of the field for weeds and bare spots detection was carried out at a speed of $0.54 \mathrm{~m} \mathrm{~s}^{-1}$. The height maps were generated in Arc View 3.2 showing weed patches, bare-spots and wild blueberry plants in selected fields.
\end{abstract}

\section{Introduction}

Wild blueberry (Vaccinium angustifolium Ait.) is a unique crop native to Northeastern North America with annual production of 82 million $\mathrm{kg}$ of fruit (market price around $\$ 352$ million) covering an area of 79,000 ha. Wild blueberry fields are developed from native stands on deforested farmland by removing competing vegetation (Eaton, 1988). The majority of fields are situated in naturally acidic soils that are low in nutrients and have high proportions of bare spots, weed patches and gentle to severe topography (Trevett, 1962; Zaman et al., 2008). This crop is perennial in nature, having a vegetative growth season (sprout year) followed by a productive season (fruit year). Considerable spatial variability of fruit yield occurs in wild blueberry fields, originating primarily from, significant bare spots, weed patches, variable plant sizes, and soil limitations.

Non-destructive measurement of crop growth stage, canopy development, and height may be useful for more efficient crop management practices (Abid Aziz et al., 2004). Ultrasonic sensors working on sound waves can be able solution for measuring crop growth parameters. Vansichen and De Baerdemaeker (1992) tried to measure the distance between crop divider (mounted on the combine header) and the un- harvested crop by aid of an ultrasonic sensor. Kataoka et al. (2002) showed that an ultrasonic sensor had good performance for soybean and corn height measurement compared to laser beam sensor.

Ultrasonic sensors have been used for the control of agrochemical application rates in sprayers and fertilizer spreaders for tree crops for two decades. Ultrasonic sensors measure horizontal distances from a given sensor to the nearest foliage by way of an ultrasonic wave sent to a target (foliage), which would reflect the wave back to the sensor. Sui and Thomassan (2006) used ultrasonic sensor (Sui et al., 1989) to measure plant height in determining Nitrogen $(\mathrm{N})$ status for cotton plants.

Taller weeds remain a serious threat for the growth of blueberry as well as for smoother mechanical harvesting causing fruit losses. Cutting was not effective and wiping could result in injury to the blueberry plant, so other safer alternatives were needed (Yarborough, 2006). There are several roller-type applicators now in use, including several tractor mounted models and small one-man portable machines for use in small fields. Automated identification of taller weeds using simple technique will help in monitoring their growth in wild blueberry fields. The bare spot areas varied from $30 \%$ to $50 \%$ of the 
total wild blueberry field area and were scattered throughout the fields (Zaman et al., 2008). Bare spots in wild blueberry field need special attention, as these are the areas where wild blueberry will expand in near future.

The objective of the research work is to develop a system to identify and map the occurrence of taller weeds and bare spots in wild blueberry field using ultrasonic sensor mounted on a farm motorized vehicle (FMV).

\subsection{Principles ultrasonic sensors}

Ultrasonic techniques have been used in the past for agricultural applications based on the basic idea of distance measurement. Distance is determined by transmitting a burst of high-frequency sound, then waiting for the echo to return from surfaces within the sensor field of view. The distance can then be computed based upon the speed of the sound and the elapsed time between sound transmission and echo return (Ciarcia, 1984).

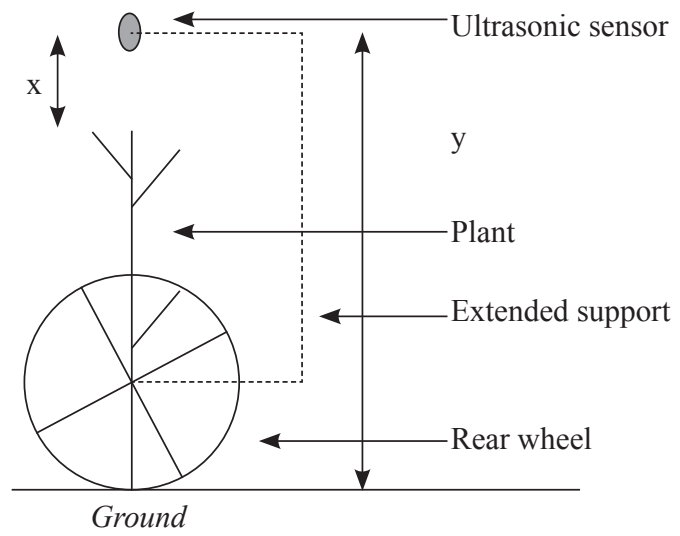

Figure 1: Technique for plant height measurement

Plant height can be calculated using the following equation (Figure 1)

Plant height $=\mathrm{y}-\mathrm{x} \quad \ldots$ (1)

Where,

$y=$ Height of the sensor from ground (fixed)

$\mathrm{x}=$ Height of the sensor from plant surface (measured)

\section{Methodology}

\subsection{Farm motorized vehicle (FMV)}

The ultrasonic sensors were mounted on the rear of a specially designed Farm Motorized Vehicle (FMV), (Figure 2). The FMV was assembled using locally available materials and parts to optimize the total system cost. The 190cc engine (Honda Inc., Nova Scotia, Canada) of FMV is capable to generate $6 \mathrm{hp}$ with a maximum rpm of 3600 and can travel at $0-10 \mathrm{~km} / \mathrm{hr}$. The slim bicycle wheels of FMV will cause little or negligible damage to crop during operation in the field. The vehicle direction and speed is controlled at the handle mounted at the center of front pair of wheels. The gasoline engine with a chain-sprocket power transmission system provides the required power to the vehicles. Special arrangement was made to mount the laptop on the vehicle. The GPS antenna can be mounted at centre of the vehicle as well as at the front of the vehicle.

\subsection{Hardware components}

Two LV-MaxSonar-EZ3 (Max Botix Inc., MN, US) ultrasonic sensors were used to measure the plant height in the wild blueberry field (Figure 3 ). The sensors were mounted besides the rear wheels of the FMV, being spaced as $0.25 \mathrm{~m}$ from the side wheel and $0.50 \mathrm{~m}$ between them to avoid overlapping of the sonar signals. A Trimble (Trimble Navigation Limited, Sunnyvale, CA) AgGPS 332 receiver was used to provide the

accurate location co-ordinates of the sensors for georeferencing. The DGPS position data were transmitted to the laptop (Dell Canada Inc., ON, Canada) RS-232 port at $1 \mathrm{~Hz}$, using the National Marine Electronics Association (NMEA0183) standard RMC code sentences along with the sensor readings.

\subsection{Software development}

Custom-built software interface was developed in graphical programming language (Zang et al., 2007) LabView 8.5 (National Instrument Inc., ON, Canada) application environment to monitor the system for a 32-bit Windows operating system (Microsoft Corp., Redmond, WA) in a laptop computer (Figure 4). The DGPS raw readings were decoded in the program to get latitude and longitude co-ordinates of the location and forward speed of the system. The ground speed (in knots) was parsed from the DGPS string and converted to metric units, using speed $(\mathrm{m} / \mathrm{s})=0.51444 \times$ speed (knots). The sensors work with an input voltage of 2.5-5.5 VDC giving output in terms analog $(0-5 \mathrm{~V})$, digital signals. The analog output of the sensor was converted to distance covered by the sonar wave being send from the sensor. The plant height from ground was calculated using the equation 1 and shown as a sliding scale in the interface for the two sensor readings. Simple averaging of the two sensor readings was used to estimate the

Figure 2: FMV mounted with ultrasonic sensors
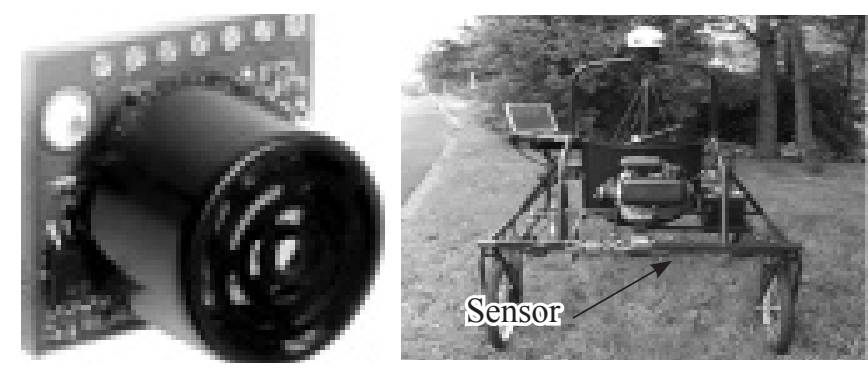

Figure 3: Ultrasonic sensor 
plant height at the location. The maximum plant height was set as $60 \mathrm{~cm}$ for the wild blueberry crop.

\subsection{Field experiment}

The system is calibrated using objects (small paper boxes $5 \mathrm{~cm}$ each) with known heights. The objects were placed, one after another, under both the sensors and heights measured as shown in the interface were simultaneously recorded. Calibration curve was developed in the SAS (SAS Institute, Cary, N.C.).

The field experiment was carried out in September 2008 in wild blueberry fields (during vegetative crop growth year) located (field 1: $45.26483^{\circ} \mathrm{N} 63.32486^{\circ} \mathrm{W}$ and field 2: $45.2644^{\circ}$ N 63.26962 W) in Central Nova Scotia. The system was operated at a forward speed of $0.54 \mathrm{~m} / \mathrm{s}$ (Zaman et al., 2005) to have stable sensor readings. Simultaneous, the readings from the sensor and GPS co-ordinates were recorded in the laptop hard disk. The data were transferred to Arc View 3.2 (ESRI, Redlands, Calif., USA) GIS software to develop the distribution map for plants with different heights. Site-specific zone maps were also developed to identify the bare spots and taller weeds and grasses from wild blueberry plants.

\section{Results and discussion}

\subsection{Sensor calibration}

The sensor was calibrated with the known small plastic bags of height around $5 \mathrm{~cm}$. Eights set of objects $(+1$, readings with no object) were selected and 5 readings for each set were taken. Average of the readings of the known heights $(5 \mathrm{~cm}, 10$ $\mathrm{cm} 15 \mathrm{~cm}$ etc.) for 5 sets, were taken from software interface. Calibration curve showed sound correlation with coefficient of determination $\left(\mathrm{r}^{2}\right)$ of 0.9953 in SAS software (Figure 5). The calibration was mainly carried in the static condition, outdoor, under the sunshine. The significant co-relation showed the suitability of measuring object height with ultrasonic sensor

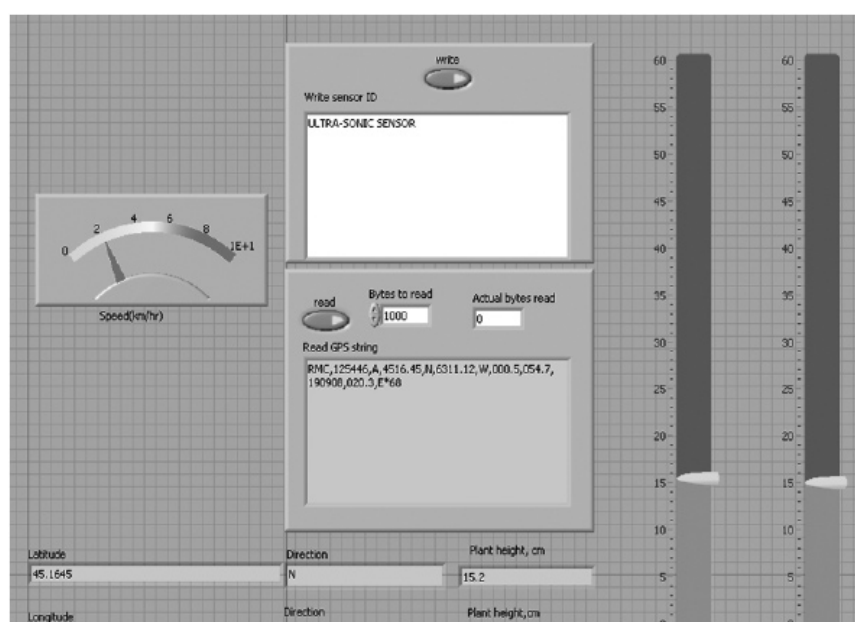

Figure 4: Custom program interface in LabView system.

Mapping of two wild blueberry fields were carried out in September 2008 to identify bare spots and taller weeds using ultrasonic technique (Figure 6). Field 1 has fewer weed patches compared to field 2 . In field 2 , it can be identified the presence of bare land besides the field being used to turn the FMV. Detecting weeds in agricultural farm is a challenging task for precision agriculture technology application. By combining other image analysis technique along with ultrasonic sensor can successfully identify all the weeds and map them for variable rate agrochemical applications.

This will substantially save total expenditure on agrochemicals instead of uniformly applying all over the field. Zaman et al. (2005) saved $40 \%$ fertilizer with variable rate (VR) fertilization as compared to the grower's uniform rate in a Florida citrus orchard. The bare spots need special attention as it will be the potential area for growth of wild blueberry. The technique is very simple and can be used in wild blueberry field for quick mapping of bare spots and weeds.

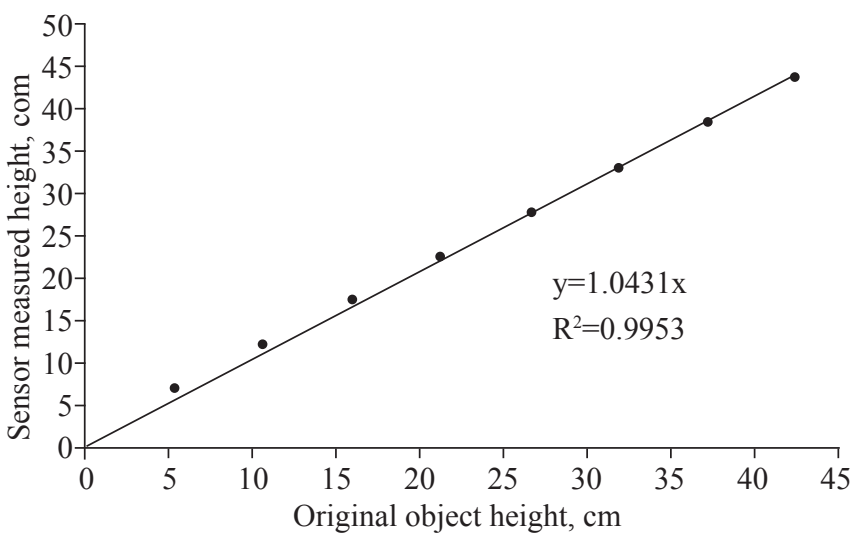

Figure 5: Calibration curve for the ultrasonic sensor

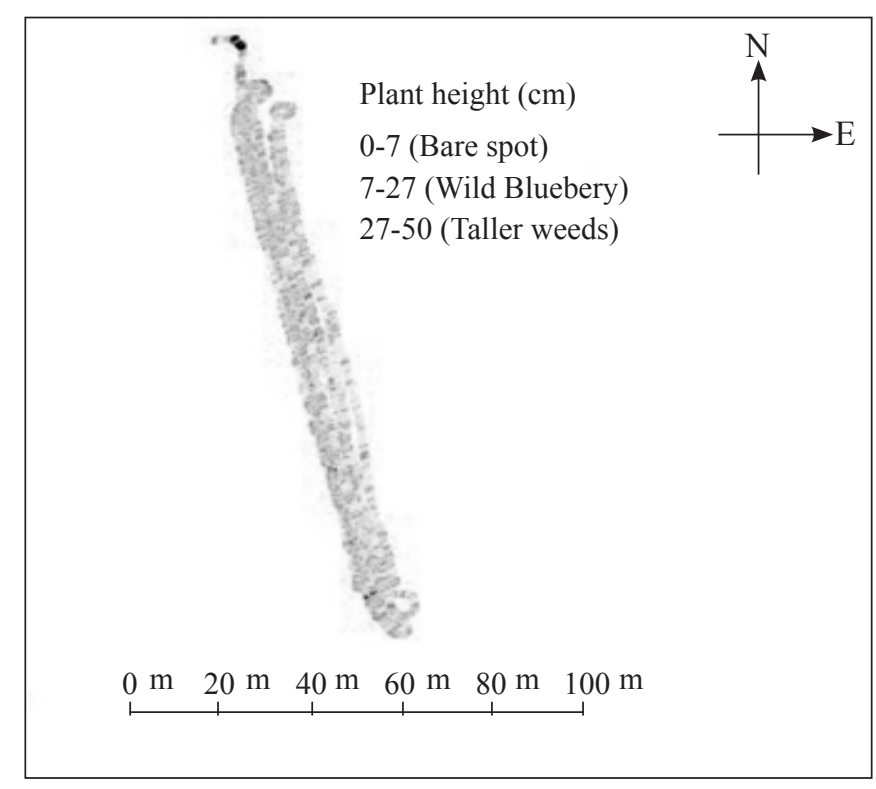




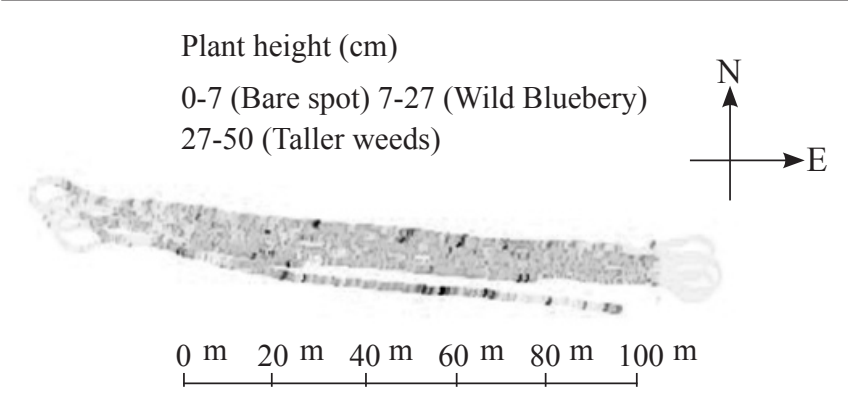

Figure 6: wild blueberry coverage map; a. field 1, b. field 2

\section{Conclusions}

Ultrasonic sensor based plant height measurement provides a simpler, cheaper and a practical option for identifying bare spot and taller weeds in wild blueberry fields. Agrochemical prescription maps can be developed for variable rate applications. The accuracy of system with a co-efficient of determination $\left(\mathrm{r}^{2}\right)$ of 0.99 will encourage the farmers and planners for wild blueberry field applications. By identifying and suppressing taller weeds will substantially reduce the wild blueberry fruit loss during the mechanical harvesting.

\section{Reference}

Abid Aziz, S., Steward, B., Birrell, S., Kaspar, T., Shrestha, D., 2004. Ultrasonic Sensing for Corn Plant Canopy Characterization, ASAE Annual International Meeting. St. Joseph, MI. Paper No. 04-041120.

Ciarcia, S., 1984. An ultrasonic ranging system, BYTE 9(11), 112-123.

Kataoka, T., Okamoto, H., Kaneko, T., Hata, S., 2002. Performance of Crop Height Sensing Using Ultra Sonic Sensor and Laser Beam Sensor. ASAE Paper No. 021184.
Chicago, IL: ASAE.

Sui, R., Thomasson, J.A., 2006. Ground-based sensing system for cotton nitrogen status determination, Transaction of ASABE, 49(6), 1983-1991.

Sui, R., Wilkerson, J.B., Wilhelm, L.R., Tompkins, F.D., 1989. A microcomputer-based morphometer for bush-type plants. Computer and Electronics in Agriculture 4(1), 43-58.

Trevett, M.F., 1962. Nutrition and growth of the lowbush blueberry. Bulletin 605. Orono, Maine: Maine Agricultural Research Station.

Vansichen, R., De Baerdemaeker, J., 1992. Measuring the actual cutting width of a combine by means of an ultrasonic distance sensor. Trends in Agricultural Engineering, Prague, 15-18 September, 615-621.

Yarborough, D.E., 2006. Innovations in weed management in wild blueberry fields in Maine, ISHS Acta Horticulture 715: VIII International Symposium in Vaccinium Culture.

Zaman, Q.U., Schumann, A.W., Hostler, H.K., 2005. Quantifying Sources of Error in Ultrasonic Measurements of Citrus Orchards, Paper Number: 051123, 2005 ASAE Annual International Meeting.

Zaman, Q.U., Schumann, A.W., Percival, D.C., Gordon, R.J., 2008. Estimation of wild blueberry fruit yield using digital color photography, Trans. of ASABE 51(5), 1539-1544.

Zang, Y., Luo, X., Zhou, Z., 2007. Information acquisition technology for precision farming in China, ASABE Meeting Paper No.073120, Minneapolis, Minnesota. 